Session \# 3566

\title{
SMART MATERIALS: TEACHING APPROACHES FOR UNDERSTANDING AND EVALUATING MECHANICAL PROPERTIES AND MICROSTRUCTURE
}

\author{
K.V. Sudhakar, Hector Cervantes \\ Department of Mechanical Engineering, \\ Universidad de las Americas-Puebla, \\ Santa Catarina Martir, Puebla 72820, Mexico
}

\begin{abstract}
This paper discusses some of the specific teaching methods and supplemental experimental methodologies for learning smart materials. This course is introduced as an elective for mechanical engineering undergraduate students who want to pursue careers in the professional research areas of materials engineering/smart materials/biomedical engineering. Teaching tools discussed in this paper include; competency based curriculum, discussion based model approach, and lecture quiz approach. This course is basically a combination of developed and redesigned course on smart materials for which the course objectives, course methodologies and learning objectives are also discussed. The specific experimental procedures for carrying out the mechanical tests and microstructure analysis are introduced. The basic objective of these supplemental experiments is to give students the hands-on experience. More importantly, considerable emphasis is given for improving students' learning skills and creative thinking by having small group discussions and frequent quizzes on laboratory exercises. The direct benefits of experimental exercises to materials science/mechanical engineering education have been discussed. Detailed course assessment for evaluating students' performance as well as for determining the effectiveness of the course is also discussed. These assessments help in regularly monitoring the course and then modify/improve the course as and when required.
\end{abstract}

Keywords: Teaching tools; Smart material; Laboratory experimental methods; Mechanical testing and microstructure; Engineering education; Methods of course assessment.

\section{Introduction}

The typical undergraduate mechanical engineering curriculum has a basic course in materials science that deals with topics like atomic bonding/structure, heat treatment, mechanical testing, and microstructure analysis in various materials viz., metals and alloys, polymers, ceramics, composites and others. However, there is an important need for mechanical engineering

"Proceedings of the 2004 American Society for Engineering Education Annual Conference \& Exposition Copyright (C) 2004, American Society for Engineering" 
undergraduates to study one of the most important advanced materials like smart materials. One of the typical applications of a shape memory alloy (used in Compact Navigation, Guidance \& Control Actuator for Miniature Kinetic Energy Missile) is shown below.

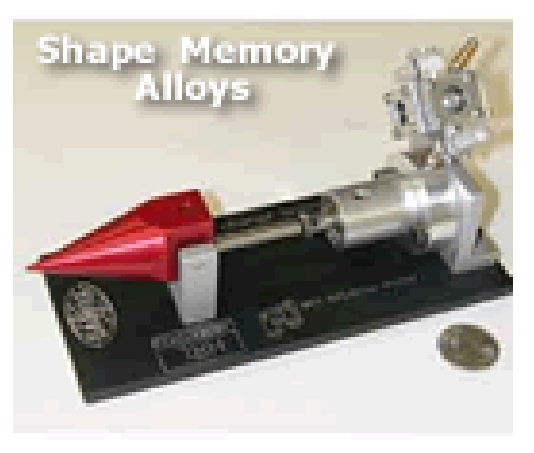

To give more examples for other types/applications of smart materials; Macro Fiber Composite (MFC) Actuator and Sensor, PZT Fibers and Tubes, SFC actuators, Composites for Ultrasound applications, and Fiber Composites are shown in the following figures, from left to right, respectively. It is useful to consider a few literatures available on smart materials used in orthodontic treatment ${ }^{1-7}$.

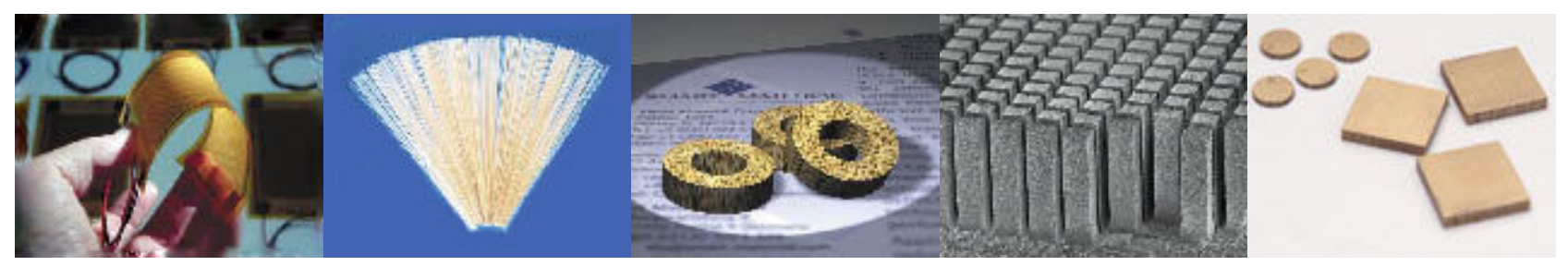

The proper understanding of mechanical properties and microstructure of smart materials is very foundational and also beneficial for designing modern smart structures. The purpose of this elective course is to nurture scientific/engineering interest on such important materials and also fulfill industrial needs in that direction. This paper discusses some of the class room lecture tools and supplemental laboratory experimental methods for enhancing student's skills to evaluate mechanical properties and microstructure of smart materials.

\section{Class-room teaching tools}

The following class-room teaching methodologies are evolved as a result of new development as well as the redesign of the undergraduate course on smart materials.

\subsection{Competency-based curriculum for smart materials}

Since smart materials are one of the advanced materials of great importance in this millennium for varieties of strategic applications, it is but natural for us to include a competency-based academic curriculum for it. One of the basic components of competency based curriculum on smart materials is to focus on the following aspects of teaching and learning:

"Proceedings of the 2004 American Society for Engineering Education Annual Conference \& Exposition Copyright (C) 2004, American Society for Engineering" 
Teaching

- Nurture curiosity, creativity, critical thinking and enterprise.

- Remain relevant to the demands of a rapidly transforming society.

Learning

- Merge academic rigor with the thrill of discovery.

- Stimulate minds and encourage cross-disciplinary discourse.

The success of this competency-based curriculum requires application of different educational strategies $^{8-10}$ :

The first step in a competency-based curriculum is the development of a set of competency statements to define what knowledge, skills and attitudes the mechanical /materials engineering undergraduate should possess. This set of competency statements will then provide a standard for identifying the core content of the curriculum and allowing the assessment of outcomes of the curriculum. Competencies in the curriculum should be reviewed and modified to be responsive and reflective of the educational needs of the students, community demands and changes in professional practices.

\subsection{Undergraduate courses on Smart materials}

Typical components of an undergraduate course on smart materials include; course objectives, learning objectives and course methodology as described below.

\subsubsection{Course objectives}

Material selection is a challenging task in developing a medical device. Many factors that are often competing need to be considered for making decisions, including mechanical properties, biocompatibility, production costs, and microstructure. This course familiarizes the student with relevant material issues and highlights the process for matching material performance with the design of a particular machinery/device/equipment. The students' knowledge of smart materials will be increased and an appreciation for the relationships between a material's structure, its properties, and the implementation of properties to achieve a desired functionality will be developed.

\subsubsection{Learning objectives}

Upon successful completion of this course, the student will be able to:

- Identify the strengths of a given class of materials regarding their use as smart materials.

- Identify the weaknesses of a given class of materials regarding their use as smart materials.

- Select a candidate smart material for a given orthodontic application.

- Factor the strengths and weaknesses of a smart material into the design of a product in orthodontic application.

"Proceedings of the 2004 American Society for Engineering Education Annual Conference \& Exposition Copyright (C) 2004, American Society for Engineering" 


\subsubsection{Course methodology}

The instruction for this course is of an interactive lecture style format. A series of guest lectures increase the breadth of knowledge presented. The first half of the semester concentrates on basic mechanical testing and on the properties of different classes of materials. The second half of the semester focuses on principles, methods of metallographic examination of smart materials.

\subsection{Discussion model approach in teaching smart materials}

A discussion model is used to understand and interpret the topic "Mechanical testing and microstructure analysis" procedures for smart materials. This model aims to make small-group discussion more meaningful and effective in light of limited spatial resources and growing class sizes. Typical class size is 15 . The course structure involved 3-hr class discussions that compliment $3 \mathrm{hr}$ weekly lectures. During each session, the 15 students' discussion group is divided into subgroups of 5 students; each sub-group is given 1 or 2 topics (under which specific problems are highlighted) to discuss. After about 15 minutes of preparation, the sub-groups are encouraged to debate/discuss the issues with each other; the professor acts as a discussion facilitator and summarizes key issues raised during the 3-hr discussion. Another more important consequence is that the teaching method should shift in emphasis from passive lecturing to mentoring and small group tutorials. Small group tutorials would also enable students to participate more actively in group discussions and further develop their listening and speaking skills.

\subsection{Lecture quiz approach}

The class-room lectures on smart materials include several lecture quizzes as a continual assessment component. Typically, 15-20 short questions (demanding specific answers) in the form of multiple-choice, true/false or computation are asked in each lecture quiz. Students are allowed to discuss the questions and hand in the answers in small groups. The main aim of the lecture quiz is to let the lecturer have a better gauge of whether the students have grasped the main concept taught in each lecture on specialty topics relating mechanical properties and microstructure of smart materials. It also promotes cooperative learning among the students as well as allows them to relate to and reflect instantly on what they have just learned.

\section{Laboratory experimental methods for learning smart materials}

Laboratory experiments (though not directly linked to teaching methods discussed in the previous section) are practiced as additional/supplemental tools to enhance the learning on smart mart materials.

\subsection{Educational contribution of experiments}

Some of the laboratory experimental methods for learning more about smart materials are practiced as additional tools to evaluate their mechanical properties and microstructure. As

"Proceedings of the 2004 American Society for Engineering Education Annual Conference \& Exposition Copyright (C) 2004, American Society for Engineering" 
mentioned in section 2.2.3, laboratory experiments are designed and conducted to learn about the mechanical properties and microstructure that are described in sections 3.2 through 3.5.

Instructional lectures on each experimental method (in a group of maximum 5 students) are given during each group's laboratory classes. Each group has one laboratory class of $3 \mathrm{hrs}$ duration per week. The ultimate goal of these practical exercises is to provide hands-on experience for students in understanding and analyzing mechanical properties and microstructures in smart materials. These also include, teaching learning skills and creative thinking during experimental projects/exercises.

\section{Teaching learning skills}

The acquisition of process skills, i.e. learning how to learn, is equally important, if not more important, than the acquisition of knowledge itself. Process skills refer to the abilities to source, analyze, screen, prioritize and apply a mass of information to solve the problem at hand. Such skills are especially important in the new era where the growth of knowledge is explosive and lifelong independent learning is essential.

\section{Teaching creative thinking}

Small group discussions are conducted to improve creative thinking skills. Creative thinking is especially important in formulating problems and exploring alternative methods.

\subsection{Tensile test}

THREE tensile tests are carried out by each group of students. The tensile tests of orthodontic wires are performed using an Instron UTM-8502 model machine using a load frame of $1000 \mathrm{~N}$ capacity. The tests are carried out as per ASTM standard E8. Standard pulley-fixtures are used for tensile testing thin metallic wires. The load-displacement curve is obtained to evaluate various tensile parameters.

\subsection{Three-point bend test for flexural strength}

THREE flexural strength tests are carried out by each group of students. Three-point bend test is carried out using an Instron UTM (Model 8502) at a displacement rate of $0.05 \mathrm{~mm} / \mathrm{min}$. Specific fixtures are designed and fabricated to suit the size of orthodontic wires. Flexural strength is the measure of how well a material resists bending, or what is the stiffness of the material. Unlike tensile loading, in flexural testing all force is applied in one direction. A simple, freely supported beam is loaded at mid-span thereby producing three-point loading.

In the present case, a rectangular sample having a rectangular cross section is bent until fracture. At the point of loading, the top surface of the specimen is placed in a state of compression, whereas the bottom surface is in tension. Stress is computed from specimen thickness, the bending moment, and the moment of inertia of the cross section. The maximum tensile stress (as determined using these expressions) exists at the bottom specimen surface directly below the point of load application. The stress at fracture using this flexure test is known as the flexural

"Proceedings of the 2004 American Society for Engineering Education Annual Conference \& Exposition Copyright (C) 2004, American Society for Engineering" 
strength, modulus of rupture, fracture strength, or the bend strength. For a rectangular cross section, the fracture stress $\sigma_{\mathrm{fs}}$ is equal to

$$
\sigma_{\mathrm{fs}}=3 \mathrm{~F}_{\mathrm{f}} \mathrm{L} / 2 b d^{2} \text { where }
$$

$\mathrm{F}_{\mathrm{f}}$ is the load at fracture; $\mathrm{L}$ is the distance between support points, $\mathrm{b}$ the specimen width, and $\mathrm{d}$ the specimen thickness/depth. It is important to note that $\sigma_{\mathrm{fs}}$ depends on specimen size. With increasing specimen volume (under stress) there is an increase in flow severity and, consequently, a decrease in flexural strength. In flexural test, since during loading, a specimen is subjected to both compressive and tensile stresses, the magnitude of its flexural strength is greater than the tensile fracture strength.

\subsection{Microhardness (Knoop) test procedure (ASTM E384-99)}

TEN microhardness measurements are carried out by each group of students. In the present case, testing is considered to be light force since the size of indentations (diagonal length) was less than $20 \mu \mathrm{m}$. Thus, hardness numbers obtained from indentations with diagonals measuring less than $20 \mu \mathrm{m}$ are much more sensitive to variations of a few tenths of a micrometer in the actual or measured length of the diagonals than hardness numbers obtained by measuring larger indentations. Ni-Ti metal wire, because of its very small size required mounting. Sufficient care is taken to ensure that the specimens were well supported in the mounting material. Also, the surface to be tested is placed into the test instrument such that it is normal to both the loading and optical axis. The optical quality of the microscope is such that highly corrected objectives with numerical apertures of 0.9 and greater are used. In addition, dark field illumination and differential interference contrast is used to improve the contrast of the image. This also helps to enhance the user's ability to detect the ends of the indentations.

Knoop hardness test is carried out on a SHIMADZU Knoop microhardness testing machine (model: 2000-seies). The Knoop microhardness test is used particularly for very thin layers. The long diagonal is seven times, as long as the short diagonal. With this indenter shape, elastic recovery can be held to a minimum. The Knoop test is conducted in the same manner, and with the same tester, as the Vickers test. However, only the long diagonal is measured, except for the projected area hardness (PAH) test. The Knoop hardness is calculated from:

$$
\mathrm{HK}=14229 \mathrm{~L} / d^{2}
$$

Where the load $\mathrm{L}$ is in gf and the long diagonal $d$ is in $\mu \mathrm{m}$.

\subsection{Microscopic examination procedure to reveal microstructural details}

THREE metallographic specimens are prepared and examined by each group of students. Microetching techniques are used to reveal general microstructure in Ni-Ti alloys. Ni-Ti alloy is treated with following three chemical etching reagents to get the best possible results. First, the

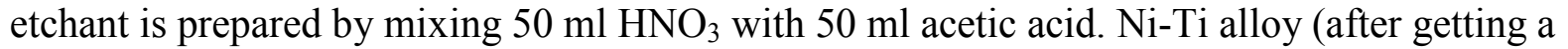
mirror surface finish from standard polishing techniques) is immersed/swabbed for about $30 \mathrm{~s}$.

"Proceedings of the 2004 American Society for Engineering Education Annual Conference \& Exposition Copyright (C) 2004, American Society for Engineering" 
Second reagent was prepared by mixing solutions of $10 \mathrm{ml} \mathrm{HF}, 25 \mathrm{ml} \mathrm{HNO}_{3}$ and $150 \mathrm{ml}$ water. The sample is swabbed for about $30 \mathrm{~s}$. Electrolytic etching is tried as a third technique for revealing general microstructure in Ni-Ti alloys. The electrolyte consists of $5 \mathrm{ml}$ acetic acid, 10 $\mathrm{ml} \mathrm{HNO} 3$ and $85 \mathrm{ml}$ water. The electrolytic etching is carried out at $1.5 \mathrm{~V}$ for $60 \mathrm{~s}$.

\section{Methods of course assessment}

The following methods are used to assess student performance and the effectiveness of the course in both lecture and laboratory classes.

\subsection{Student performance}

For the lecture classes, students are given 3 tests (one each month) and a comprehensive final exam besides a project work (includes written report and oral presentation during the last week of each semester) on selected topics of smart materials at the end of the semester.

Typical laboratory quizzes, each of about $15 \mathrm{~min}$ (with about 15 questions) is given at the end of each laboratory experiment/exercise. These are usually multiple choice type questions to evaluate students' understanding/perception of each experiment. A small group technical discussion is encouraged at the end of each experiment to refresh student's understanding/perception. Students of each group are required to turn-in their written laboratory report before the commencement of next experiment. At the end of the course, individual as well as cumulative performance of students is evaluated based on quizzes.

\subsection{Effectiveness of the course}

The course was evaluated during the mid-semester period and also at the end of each semester to sustain optimum quality. Numeric values have been assigned to the various rating scales for the purpose of computing medians. The scale values are as follows:

$$
\begin{aligned}
\text { Excellent } & =5 \\
\text { Very Good } & =4 \\
\text { Good } & =3 \\
\text { Fair } & =2 \\
\text { Poor } & =1
\end{aligned}
$$

The typical questions used for evaluating the course are:

1. The objectives/learning outcomes for each part of the course were clear.

2. The required tests, quizzes, projects, accurately measured my attainment of these learning outcomes.

3. The course was well organized.

4. The required reading and assignments contributed to my learning.

5. The class room discussions contributed to my learning.

6. The instructor inspired interest in the course material.

7. The instructor provided timely feedback.

"Proceedings of the 2004 American Society for Engineering Education Annual Conference \& Exposition Copyright (C) 2004, American Society for Engineering" 
8. The instructor's feedback was clear and useful.

9. The instructor treated students with respect.

10. The instructor provided opportunities for students to learn from each other.

11. The instructor was available and helpful.

The feedback from the above has been useful in continuously monitoring and incorporating appropriate changes to improve the course.

\section{Conclusions and remarks}

At the outset, the competency based curriculum is vital for teaching smart materials. Learning experiences should be differentiated from CORE competencies. These are desirable technical and behavioral knowledge, skills and attitudes that students should experience, learn or be exposed to without the expectation of reaching competency. The learning environment has changed from an apprenticeship model and passive learning to one that integrates learning strategies with outcomes. With competency outcomes as a guide, the curriculum is more dynamic. Staffs can be more reflective and help in changing their teaching strategies for good, if required.

Amongst teaching methodologies, discussion model and lecture quiz approaches are considered as effective tools for learning smart materials. Laboratory experiments are designed specifically to focus on learning skills and creative thinking among students during their professional practice of engineering/science.

The unique properties of Ni-Ti alloy smart material have provided the enabling technology for many groundbreaking applications in the medical and dental industries. These applications have included everything from surgical tools to permanent implants, including implants within the bloodstream.

\section{References}

1. C. J. Whitters, R. Strang, D. Brown, R.L. Clarke, R.V. Curtis, P.V. Hatton, A.J. Ireland, C.H. Lloyd, J.H. McCabe and J.W. Nicholson. Dental materials-1997 literature review, 27(6) 401 (1999).

2. C. J. Whitters, R. Strang, D. Brown, R.L. Clarke, R.V. Curtis, P.V. Hatton, A.J. Ireland, C.H. Lloyd, J.H. McCabe and J.W. Nicholson Dental materials-1996 literature review,26(3) 191 (1998).

3. M. Iijima, H. Ohno, I. Kawashima, K. Endo and I. Mizoguchi, Mechanical behavior at different temperatures and stresses for superelastic nickel-titanium orthodontic wires having different transformation temperatures. Dent Mater, 18(1) 88 (1992).

4. F. Miura, M. Mogi, Y. Ohura and H. Hamanaka, The super-elastic property of the Japanese NiTi alloy wire for use in orthodontics. Am J Orthod, 901 (1986).

"Proceedings of the 2004 American Society for Engineering Education Annual Conference \& Exposition Copyright (C) 2004, American Society for Engineering" 
5. R. C. Sachdeva and S. Miyazaki. Superelastic Ni-Ti alloys in orthodontics. In: T.W. Duerig, K.N. Melton, D. Stockel, C.M. Wayman, Editors. Engineering aspects of shape memory alloys. ButterworthHeinemann, London, 452 (1990).

6. S.E. Khier, W.A. Brantley and R.A. Fournelle. Bending properties of superelastic and nonsuperelastic nickel-titanium orthodontic wires. Am J Orthod Dentofacial Ortho, 99310 (1991).

7. S. Miyazaki and K. Otsuka. Development of shape memory alloys. ISIJ Int, 29353 (1989).

8. Commission on Dental Accreditation Standards for Dental Education Programs. (1986). Chicago: American Dental Association.

9. Snow, R.E. (1989). 'Toward Assessment of Cognitive and Conative Structures in Learning'. Educ Researcher 18:8-14.

10. Gaver, D.P., Dee, KC, Hart, R.T., and O'Neal, E. "Implementing Experiential Learning in Biomedical Engineering," a proposal to the National Science Foundation, 2000.

\section{Biography of Dr. K.V. SUDHAKAR}

Dr. K. V. Sudhakar is an Associate Professor-III in the Department of Mechanical Engineering at Universidad de las Americas-Puebla in Puebla, Mexico. He has over 20 years of professional experience in Teaching, Research and Industries. He has worked between 1999-2001 as an Assistant Professor at Western Michigan and Central Michigan Universities in Michigan, USA. Dr. Sudhakar received his Ph.D. degree in Engineering (Fatigue \& Fracture) in 1996 from Indian Institute of Science at Bangalore, M. Tech (Materials \& Metallurgical Engineering) in 1991 from Indian Institute of Technology at Kanpur and B. Tech (Metallurgical Engineering) degree in 1981 from Karnataka Regional Engineering College at Surathkal, in India. Dr. Sudhakar has over 20 peer reviewed technical papers which were published in some of the reputed international journals during the year 1999-2002. He is a technical reviewer for International Journal of Fatigue. Dr. Sudhakar is a recipient of Outstanding Faculty Research Award at Central Michigan University, Michigan (USA) for the academic year 2000-2001. His teaching and research interests include Mechanical Behavior of Materials, Mechanics of Fatigue and Fracture, Biomaterials/Dental materials, Materials Processing, Mechanical Testing \& Evaluation, Powder Metallurgy/Metal Injection Molding, Structure-Property Relationship, Materials Science, Failure Analysis, and Physical Metallurgy.

\section{Biography of Eng. HECTOR CERVANTES}

Eng. Hector Cervantes is a graduate from Instituto Tecnológico de Puebla in Industrial Mechanical Engineering. He worked as an Industrial Mechanical Engineer in the area of Science of Materials. Also, he worked as the Head of Laboratories of Basic and Advanced Manufacturing at the same Institution. At present, Eng. Cervantes is a Laboratory Professor at Universidad de las Ameritas-Puebla for the last 7 years. He is the HEAD of the laboratory for Materials Science \& Engineering. Also, he is the Project Director for projects related to Electratón and Mini Baja. Eng. Cervantes research interests include Materials Science, Physical and Mechanical Metallurgy, Designing of Automobiles. 